\title{
1 ADM1 modelling of large-scale covered in-ground anaerobic reactor treating sugarcane
}

2 vinasse

3 Marcelo Leite Conde Elaiuy $^{\mathrm{a}^{*}}$, Aiduan Li Borrion ${ }^{\mathrm{b}}$, Davide Poggio ${ }^{\mathrm{c}}$, Julia Anna Stegemann ${ }^{\mathrm{d}}$, Edson

4 Aparecido Abdul Nour

$5{ }^{a}$ University College London, Department of Civil, Environmental \& Geomatic Engineering, Centre

6 for Resource Efficiency \& the Environment (CREE), Chadwick Building, Gower Street, London

7 WC1E 6BT, United Kingdom-m.elainy@ucl.ac.uk

$8{ }^{b}$ University College London, Department of Civil, Environmental \& Geomatic Engineering, Centre

9 for Resource Efficiency \& the Environment (CREE), Chadwick Building, Gower Street, London

10 WC1E6BT, United Kingdom-a.borrion@ucl.ac.uk

$11{ }^{c}$ Energy 2050, Department of Mechanical Engineering, Faculty of Engineering, University of

12 Sheffield, Sheffield S10 2TN, UK - d.poggio@sheffield.ac.uk

$13{ }^{d}$ University College London, Department of Civil, Environmental \& Geomatic Engineering, Centre

14 for Resource Efficiency \& the Environment (CREE), Chadwick Building, Gower Street, London

15 WC1E6BT, United Kingdom-j.stegemann@ucl.ac.uk

$16{ }^{e}$ University of Campinas, School of Civil Engineering, Architecture and Urban Design, Saturnino

17 de Brito, 224, Cidade Universitária Zeferino Vaz, Campinas SP, 13083-889, Brazil-

18 ednour@fec.unicamp.br

19

20

21

22

*Corresponding author: m.elaiuy@ucl.ac.uk(M.L.C. Elaiuy) 


\section{ABSTRACT}

In this paper, we demonstrate in a clear procedure the application of ADM1 to model a large-scale covered in-ground anaerobic reactor (Cigar), processing sugarcane vinasse from a biorefinery in Brazil. The biochemical make-up (carbohydrates, proteins, and lipids) of the substrate was analysed based on the food industry standards. Two distinct subsets of data, based on the sugarcane harvest season for bioethanol and sugar production in 2012 and 2014, were used to direct and cross validate the model, respectively. We fitted measured data by estimating two key parameters against biogas flow rate: the degradation extent $\left(f_{\mathrm{d}}\right)$ and the first order hydrolysis rate coefficient $\left(k_{\text {hyd }}\right)$. By crossvalidation we show that the fitted model can be generalised to represent the behaviour of the reactor under study. Therefore, motivated by practical and industrial application of ADM1, for both different reactors types and substrates, we show aspects on the implementation of ADM1 to a specific large-scale reactor for anaerobic digestion of sugarcane vinasse.

Keywords ADM1, anaerobic digestion, biogas; simulation, sugarcane vinasse

\section{INTRODUCTION}

Sugarcane bioethanol has been produced in many countries/regions, such as Brazil, the USA and the European Union and is regarded as one of the most promising alternatives to replace fossil fuels. However, such interest has led to bioethanol expansion and the saying "what goes in must come out", is especially true for the sugar-bioethanol industry, which produces huge amounts of residues, including sugarcane vinasse (SV), a dark brown wastewater after bioethanol distillation. The projections by the Agricultural Trade Office (ATO/São Paulo) of total bioethanol production in Brazil's marketing year (MY) 2017/18 were 26.65 billion litres (11.83 billion litres of anhydrous bioethanol and 14.82 billion litres of hydrated bioethanol) (GAIN 2017). On average Brazilian biorefineries produce $12 \mathrm{~L}$ of SV for each litre of bioethanol. The trade-off between the concentration of alcohol and the viability of yeast limits the reduction of SV volumes.

SV has been extensively worldwide used as fertilizer in the sugarcane fields given the presence of rich minerals, such as potassium, calcium, magnesium, phosphorus, and nitrogen. SV can also be 
applied onto so-called "sacrifice areas" in Brazil when not used as fertilizer. However, in both cases there is a great risk of environmental contamination. The emission and degradation of SV in the terrestrial and aquatic environment can cause severe impacts, such as eutrophication of rivers and lakes, ground water contamination and GHG (greenhouse gas) emissions (Moraes et al. 2015). Nevertheless, effective and economic biological treatment of SV, such as anaerobic digestion (AD) has been often cited as an option for mitigating the environmental impacts (Leite et al. 2015, Moraes et al. 2015).

$\mathrm{AD}$ arises as a sustainable bioprocess to unlock the value of SV as an energy feedstock. It is a biological engineering solution that improves the attractiveness of bioethanol as an alternative fuel, both as a means of pollution potential reduction and through recovery of biogas for renewable bioenergy generation (Barrera et al. 2015, Leite et al. 2015). Moreover, biogas produced by AD can replace the burning of bagasse, which is a by-product from the first-generation bioethanol production, to encourage second-generation bioethanol production from bagasse (Moraes et al. 2015). However, the industrial exploitation of SV has been hampered by inefficient reactors and/or their improper operation. An experimental approach coupled with mathematical models can support optimisation of a biological system and the prediction of reactor behaviour/efficiency under different conditions (Donoso-Bravo et al. 2011). Nevertheless, the industrial application of models is not widespread given the diversity and specific nature of most industrial processes (Batstone \& Keller 2003). In addition, the complexity and non-linearity of the AD process and the considerable demand of experimental data for modelling purposes are barriers to modelling at industrial scale. To date, the Anaerobic Digestion Model No. 1 (ADM1) (Batstone et al. 2002) is commonly regarded as the most realistic and generic model to describe the main biochemical and physicochemical processes, and gas-liquid mass transfer in anaerobic digestion (Poggio et al. 2016). According to Batstone et al. (2006), ADM1 was originally developed: 1) for full-scale application in plant design, operation, and optimisation, 2) as a working platform for model improvement based on validation studies, and 3) to fulfil the industry needs as a technology transfer tool, 
developing operational strategies and evaluating the performance of controllers (Batstone \& Steyer 2007). Although the ADM1 Scientific Technical Report (STR) states that the model was developed for application in industry (Batstone et al. 2006), its industrial use to describe a large-scale covered in-ground anaerobic reactor (Cigar) to process wastewater from sugarcane biorefinery has not been reported in the literature. In addition, the practical application of ADM1 under real operating conditions is a difficult task, and the modelling framework presented here addresses some of the issues generating substantial information assessing the viability of model application using real plant data.

The research reported in this paper applies ADM1 in a clear procedure to model the first large-scale Cigar in Brazil, which processes SV to produce biogas and generate bioelectricity for supply to the local grid. The Cigar is one of the components integrating a full biogas plant.

Good modelling practice requires both direct and cross validation and to this end a reasonable volume of data must be available and divided into two subsets. Direct validation consists in evaluating the ability of the model to reproduce the experimental data used for estimating the parameters. It is a necessary condition but not enough to accept the ability of the model to reproduce the behaviour of the system under study. In fact, even fitting well the data used for parameter estimation, the model may not be generalized to represent the behaviour of the system under study by using another subset. Therefore, in this work two subsets of data, based on the sugarcane harvest season for bioethanol and sugar production in 2012 and 2014, were used to direct and cross validate the model, respectively.

\section{METHODS}

\section{Cigar set-up and operation}

The modelled large-scale anaerobic methanogenic reactor for digestion of SV, Cigar, is located in the area of Ester Mill in the city of Cosmópolis, South East, Brazil. It was designed based on historical qualitative and quantitative data for SV produced by Ester mill, and its design characteristics are shown in Table 1. In the study periods presented here of 2012 (from May 2012 to 
December 2012) and 2014 (from August 2014 to November 2014), the Ester Mill sugar production was 110,400 and 100,200 tonnes, respectively. Within the same periods, the hydrous bioethanol production was 69 million and 62 million litres, respectively.

104 Table 1. Cigar design parameters and main operational data.

\begin{tabular}{lcc}
\hline Parameter & Value & Units \\
\hline Flow rate of SV & 39.5 & $\mathrm{~m}^{3} \mathrm{~h}^{-1}$ \\
Concentration of organic matter & 30 & $\mathrm{~kg} \mathrm{COD} \mathrm{m}^{-3}$ \\
Organic Loading Rate (OLR) & 1.99 & $\mathrm{~kg} \mathrm{COD} \mathrm{m}^{-3} \mathrm{day}^{-1}$ \\
Reactor volume & 15,000 & $\mathrm{~m}^{3}$ \\
Headspace volume & 4,800 & $\mathrm{~m}^{3}$ \\
Hydraulic Retention Time & 15 & $\mathrm{days}^{3}$ \\
Conversion rate & 0.228 & $\mathrm{~m}^{3} \mathrm{CH}_{4} \mathrm{~kg} \mathrm{COD}^{-1}$ \\
Biogas rate production & 491 & $\mathrm{Nm}^{3} \mathrm{~h}^{-1}$ \\
Methane rate production $(55 \%)$ & 270 & $\mathrm{~N} \mathrm{~m}^{3} \mathrm{~h}^{-1} \mathrm{CH}_{4}$ \\
\hline
\end{tabular}

The reactor is operated under mesophilic conditions at approximately $37^{\circ} \mathrm{C}$. The average hydraulic retention time (HRT) was 15 days and Cigar was inoculated with sludge from industrial and domestic sewage treatment plants for the first time in 2010. The blanket of microorganisms in the reactor reached maturity after one and a half years (i.e., steady-state).

Figure 1 presents a simplified schematic flow diagram for Cigar and the other components (mix tank, hydrogen sulphide scrubber, and gas engine) of the biogas plant. Cigar is a 3-chamber reactor where chamber 1 and 2, represent $60 \%$ and $20 \%$ of total reactor volume, respectively. The remaining $20 \%$ volume of chamber 3 is responsible for settling most of the biological activated sludge. The SV from the biorefinery is mixed with liquor from chamber 1 to recirculate the alkalinity, with effect of an overall rise in the influent $\mathrm{pH}$. This mixture enters Cigar from the bottom and flows upwards, as in a typical upflow anaerobic sludge blanket (UASB) reactor, without the phase separator at the top, providing favourable physical and chemical conditions for sludge flocculation. An automated pumping station adjusts flow rates in Cigar, which was measured online using an electromagnetic flow meter model OPTIFLUX KC1000F/6 (Krohne) with a signal converter IFC 100. The flow rate was adjusted based on the organic loading in the SV. Over the study periods, in 2012 and 2014, there were significant variations in the COD concentration and flow rate as can be observed in Figure 2. 
122 The biogas produced is drawn from the reactor headspace and transferred to an aerobic biological

123 scrubbing system for removal hydrogen sulphide. The biogas is then burned in a gas engine

124 connected to a $1 \mathrm{MWe}$ containerized power generation set to produce bioelectricity feeding the

125 local energy grid.

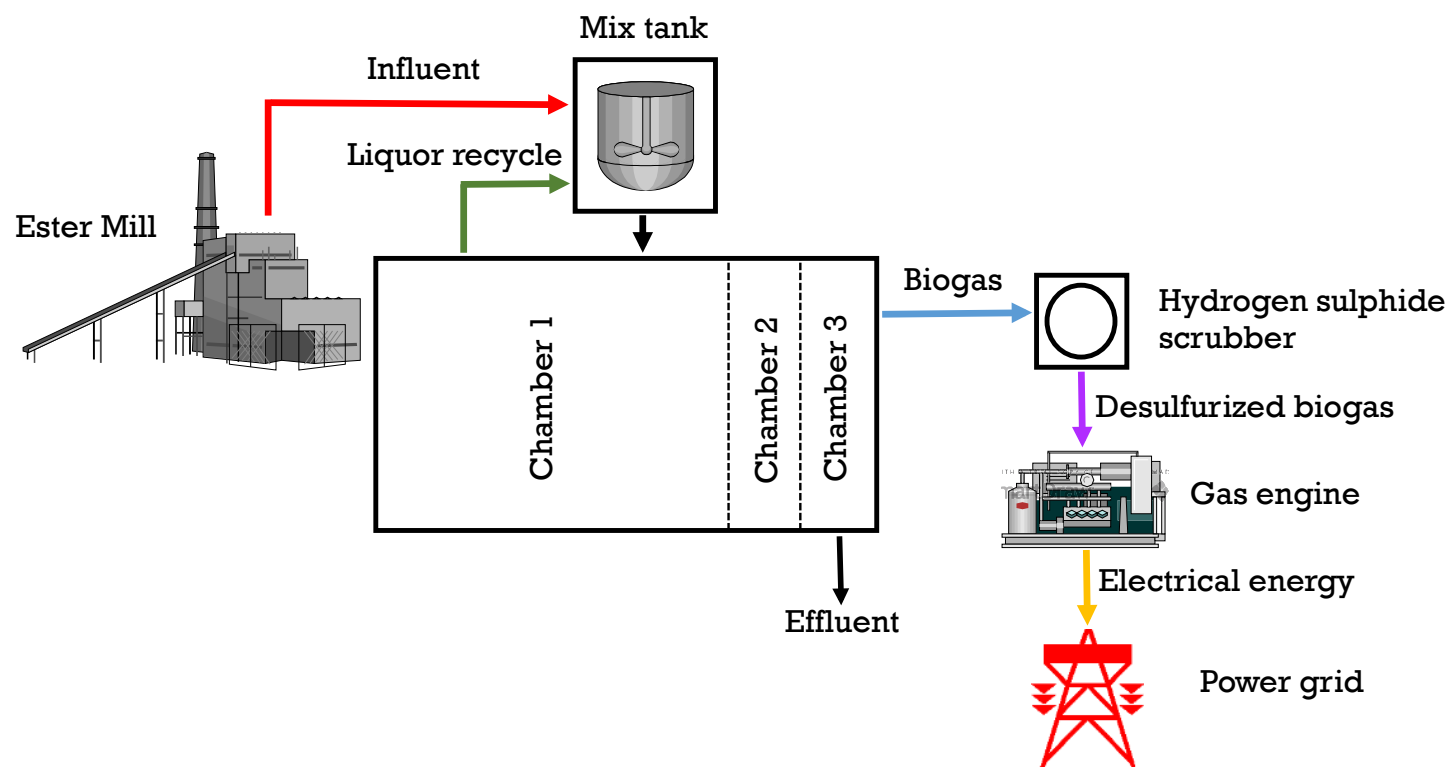

126 Figure 1. Simplified biogas plant-wide layout under study.

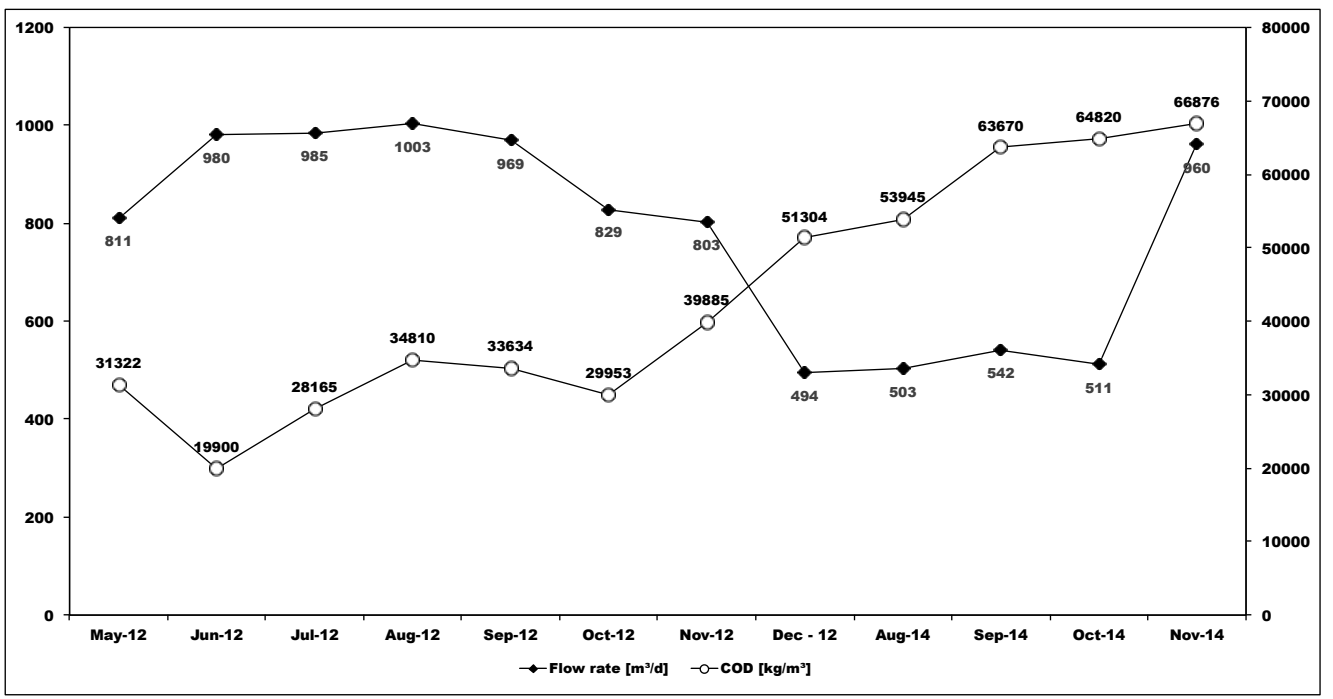

Figure 2. Averages of COD concentrations and flow rate in 2012 and 2014.

Cigar monitoring

\section{Influent and effluent}

132 The mixed influent from the mix tank and the effluent from chamber 3 were sampled, analysed, and

133 recorded based on the biogas plant operating routine, containing the most relevant information at

134 the lowest cost of monitoring. Since the reactor was located in a remote area, the biogas plant 
counted on a laboratory scale to carry out same day analyses to avoid either sample storage or transport. Recorded data from online and offline analyses provided by the plant operators were used in the model simulations. The sample collection and physico-chemical analyses of the mixed influent in the mix tank and the effluent in chamber 3, were done frequently by plant operators according to the protocols described by the Standard Methods for the Examination of Water and Wastewater (APHA 2012) - Table 2.

Table 2. Physico-chemical parameters analysed, method and frequency.

\begin{tabular}{lcl}
\hline Parameter & (APHA, 2012) & Frequency \\
\hline Temperature & 2550 & constant (online) \\
pH & 4500 & constant (online) \\
COD concentration & 5220 & daily (offline) \\
Total solids (TS) & $2540 \mathrm{~B}$ & weekly (offline) \\
Total volatile solids (TVS) & $2540 \mathrm{E}$ & weekly(offline) \\
Total suspended solids (TSS) & $2540 \mathrm{D}$ & weekly (offline) \\
Volatile suspended solids (VSS) & $2540 \mathrm{E}$ & daily (offline) \\
Volatile fatty acids (VFA) & 5560 & daily (offline) \\
Partial alkalinity & 2320 & daily (offline) \\
Total Kjeldahl nitrogen (TKN) & 4500 & fortnightly (offline) \\
Total ammonia nitrogen (TAN) & 4500 & fortnightly (offline) \\
\hline
\end{tabular}

The biochemical composition of the substrate was divided amongst, carbohydrates, lipids and proteins, and analyzed according to the following analytical methods: carbohydrates by the Lane \& Eynon (1923) method and lipids by the Bligh \& Dyer (1959) method. The total protein content was estimated by multiplying the total Kjeldahl nitrogen by factor 6.25 , based on the food industry standard for protein determination (Mariotti et al. 2008). The inert fraction in the influent was calculated as ash content (i.e., the difference between the average of TS and VS).

\section{Biogas}

149 The biogas flow was measured online using a Vortex M84 flow meter (Foxboro®) and its content $150\left(\% \mathrm{CH}_{4}\right)$ was measured using a Landtec $\mathrm{GEM}^{\mathrm{TM}}$ 2000. Equipment calibrations were undertaken 151 constantly to ensure accuracy in the measurements.

\section{Modelling methods}

\section{Cigar implementation and inputs}


Cigar was implemented as a single stage model in Aquasim $2.1 \mathrm{~d}$ (Reichert 1998) and modelled as a mixed liquid reactor with constant volume, and gas diffusion to a mixed gas headspace. For model simplicity and simulation efficiency the three chambers in the Cigar were lumped together and modelled as a CSTR reactor. In fact, samples at different points (chamber 1, recycle point, and chamber 3) were analysed for COD, TSS, and VSS (results not shown); the results were comparable in their values and showed a certain degree of sludge dispersion in the reaction zone. For this main reason we believe that our reactor should be modelled as a CSTR. Reactors such as UASBs can behave as CSTR, given their hydrodynamics influenced by the fluid flow characteristics, particles sizes, multiphase interactions, chaotic advection, and substrate dispersion (Heertjes \& Kuijenhoven 1982, Peña et al. 2006).

The original ADM1 as described in the IWA STR (Batstone et al. 2002) was used in this paper. Different researchers have developed and proposed a series of extensions to functionally upgrade the ADM1 to allow for plant-wide phosphorus (P) simulation (Flores-Alsina et al. 2016, Solon 2017) and the influence of ionic strength (as activity corrections) and ion pairing (Solon et al. 2015). However, those updates were not implemented in this study, given the lack of $P$ measurements in the available experimental data and the relative low ionic strength of the SV. Regarding the latter, Solon et al. (2015) recommends to implement the correction for ADM1 in case of high ionic strength (e.g. I > $0.2 \mathrm{~mol} \mathrm{L-1)}$ such as in manure and high-solids digestion.

Likewise, different inhibition parameters and functions, compared to the original ADM1 implementation have been recommended, for instance, for ammonia (Wett et al. 2014, Wilson et al. 2012) and VFA (Pratt et al. 2012). Especially regarding ammonia, there are experimental evidences that free ammonia inhibition coefficients are higher than previously believed (Batstone et al. 2010). However, given the lack of consensus in the scientific community, the original implementation was maintained in our study.

Stoichiometric and kinetic parameters were based on the work of Rosén \& Jeppsson (2006). The ADM1 composite material $X_{c}$, which describes the substrate, was discarded as suggested in Poggio 
et al. (2016), avoiding a two-step solubilisation processes; instead the substrate was described directly in terms of its carbohydrates, proteins, lipids and inerts fraction. The ash fraction was included in the loadings to predict the accumulation of the non-biodegradable fraction of the substrate in the Cigar. TS, VS measurements and the calculated ash fraction were read into Aquasim as real list variables.

Initial conditions were established by running a whole year steady-state simulation of the same system, and considering a constant loading rate equal to the average of the measured loading rates of 2012 and a constant substrate composition equal to the average of the measured compositions of 2012 - the outputs of that simulation were used as initial conditions for the simulations here presented and kept the same in the two data sets.

The temperature was set to $310 \mathrm{~K}\left(37^{\circ} \mathrm{C}\right)$ based on average historical mesophilic conditions measured for Cigar. Real list variables were read into Aquasim for daily COD measurements and daily feed flow rates, which were highly variable over the Cigar operation.

\section{Substrate fractionation}

The fractionation of the substrate into three biochemical compound groups: carbohydrates, proteins, and lipids is a critical step for appropriate ADM1 implementation (Ramirez et al. 2009a). ADM1 is COD-based to describe the organic matter transformations. Therefore, the elemental formula of each biochemical compound, which allocates the calculated theoretical oxygen demand (ThOD), was used to obtain concentrations in $\mathrm{kgCOD} \mathrm{m} \mathrm{m}^{-3}$. The proportions of individual organic fractions (i.e., carbohydrates, proteins, and lipids in $\mathrm{kg} \mathrm{m}^{-3}$ ) were multiplied by the ThOD of each compound.

\section{Charge balance}

The charge balance was included for the description of the substrate loadings. The following dynamic state variables in ADM1, $S_{a c}, S_{p r o}, S_{b u}, S_{v a}, S_{i n}$, and $S_{i c}$ have a charge, whilst all other variables are electro-neutral (Nopens et al. 2009). One of the approaches for modelling acid-base equations is the charge balance, described by Eq. (1) for anaerobic digestion. The unknown variables are $S_{\mathrm{CAT}}, S_{\mathrm{AN}}$, and $\mathrm{pH}$, with two degrees of freedom. In our case, the $\mathrm{pH}$ values of the 
influent stream were used (setting $\alpha$-values, $\mathrm{OH}^{-}$, and $\mathrm{H}^{+}$) to remove a degree of freedom. The other degree of freedom was removed when $S_{\mathrm{CAT}}$ exceeded $S_{\mathrm{AN}}$, then $S_{\mathrm{AN}}$ was set to zero and vice versa to close the charge balance (Poggio et al. 2016).

$S_{\mathrm{CAT}}-S_{\mathrm{AN}}=S_{a c} \alpha_{a c}+S_{p r o} \alpha_{p r o}+S_{b u} \alpha_{b u}+S_{v a} \alpha_{v a}+S_{I N} \alpha_{I N}+S_{I C} \alpha_{I C}+O H^{-}+H^{+}$

Only total VFA was routinely analysed by plant operators and most VFA in SV was assumed to be mostly acetate, as shown in Leite et al. (2015). Inorganic carbon $S_{\text {IC, }}$ calculated through partial alkalinity measurements (real alkalinity for anaerobic reactors $5.75<\mathrm{pH}$ initial $<8$ ) was set to zero, as the $\mathrm{pH}$ of the influent was always below 5. The TAN measured in the substrate was entered as $S_{\text {IN }}$ (inorganic nitrogen fraction). The specific charge coefficient $\alpha_{i}$ was calculated as described in Nopens et al. (2009). The hydrogen and hydroxide ions were determined as $\mathrm{H}^{+}=10^{-\mathrm{pH}}$ and $\mathrm{OH}^{-}=$ $10^{(-\mathrm{pKw}+\mathrm{pH})}\left(\mathrm{pK}_{\mathrm{w}}=14\right)$.

The dynamic state variables changed according to feed streams, thereby $S_{\mathrm{CAT}}$ and $S_{\mathrm{AN}}$ were calculated at given dates taking into account $\mathrm{pH}, \mathrm{VFA}$, inorganic nitrogen, inorganic carbon, and accurate temperature measurement in the laboratory. Inputs for $S_{\mathrm{CAT}}$ and $S_{\mathrm{AN}}$ were read into Aquasim as real list variables.

\section{Kinetic fractionation}

The COD input of SV, as in any anaerobic digestion system of organic residues, was divided into biodegradable and non-biodegradable fractions (Angelidaki \& Sanders 2004). The degradation extent $\left(f_{\mathrm{d}}\right)$ was introduced to describe the degradable ThOD fraction of substrate that is converted to methane (Jensen et al. 2011). This degradable fraction is made up of soluble fraction $f_{\mathrm{s}}$ and a particulate fraction $\left(1-f_{\mathrm{s}}\right)$. The non-degradable fraction $\left(1-f_{\mathrm{d}}\right)$ is composed essentially of an inert fraction $X_{\mathrm{I}}$. The literature shows that hydrolysis and disintegration rates originally suggested in ADM1 are too high and are more likely to describe activated sludge substrate (Vavilin et al. 2008, Köch et al. 2010). The disintegration step was omitted assuming direct hydrolysis of proteins $\left(X_{p r}\right)$, carbohydrates $\left(X_{c h}\right)$, and lipids $\left(X_{l i}\right)$ (Jensen et al. 2011). The particulate components of the substrate 231 (i.e., carbohydrates, proteins, and lipids) have different hydrolysis rates (Mata-Alvarez et al. 2011). 
232 However, without experimental measurements of the products of hydrolysis (sugar, aminoacids,

233 LCFA) the calibration of the three hydrolysis parameters would result in a higher uncertainty in the 234 obtained values of the parameters. Therefore, to increase the parameters identifiability, only one 235 "lumped" first order hydrolysis rate parameter is considered and calibrated. A similar approach is 236 also followed by Lübken et al. (2007), Arnell et al. (2016), Batstone et al. (2009). In addition, the 237 hydrolysis of particulate substrate, which is described as rate-limiting step in anaerobic digestion 238 (Vavilin et al. 2008), was implemented by a first order hydrolysis kinetics.

\section{Parameter estimation}

240 Preliminarily, the state at the end of the first period (2012) was assumed as the initial condition for parameter estimation. Further, we estimated two key parameters used to indicate the degradable COD: the degradation extent $\left(f_{\mathrm{d}}\right)$ and the first order hydrolysis rate coefficient $\left(k_{\mathrm{hyd}}\right)$, in attention to

244 the evidence that kinetic parameters used to describe hydrolysis of carbohydrates, proteins, and 245 lipids are assumed as unrealistic values in the original ADM1 (Kazadi Mbamba et al. 2016). Both 246 parameters were estimated and validated against biogas flow rate. They were estimated by a 247 function implemented in Aquasim to minimize the sum of the squares of weighted deviations 248 between measurements and calculated model outcomes (Reichert, 1998).

$X^{2}=\sum_{i=1}^{n}\left(\frac{y_{m, i}-y_{i}(p)}{\sigma_{m, i}}\right)^{2}$

where $y_{m, i}$ is the $\mathrm{i}^{\text {th }}$ measured value of the target measurement, assumed to be a normally distributed random variable; $y_{i}(p)$ is the model prediction at the time corresponding to data point $i$, which could be considered a function of the set of parameters $p$ to be estimated; $\sigma_{\mathrm{m}, \mathrm{i}}$ is the standard error of the measurement $y_{m, i}$ and weights each term of the sum.

254 The secant algorithm in Aquasim was selected for numerical minimization of Eq. (2) due to possible nonlinearity of the model equations and numerical integration procedure (Lübken et al. 2007). The standard error of the estimated parameters are calculated by Aquasim as an output of the 
secant algorithm, and then divided by the estimated values to determine the uncertainty in the parameters. We therefore present a more reliable evidence of representing model uncertainty than providing only model goodness of fit values (Jensen et al. 2011).

\section{Model validation}

To assess the accuracy of predictions for direct and cross validation using two subsets of data based on the sugarcane harvest season in 2012 and 2014, the relative absolute error (rAE) between measured and simulated values was determined as per Eq. (3), where $y_{m, i}$ is the $i^{\text {th }}$ measured value, assumed to be a normally distributed random variable; $y_{i}(p)$ is the model prediction at the time corresponding to data point $i$, which could be considered a function of the set of parameters $p$ to be estimated and $n$ is the number of observations. This allow us to classify the quality of predictions according two classes (Batstone \& Keller 2003): high ( $\pm 10 \%)$ or medium $(10 \%-30 \%)$ accurate quantitative prediction.

$r A E=\frac{\sum_{i=1}^{n}\left(\frac{\left|y_{m, i}-y_{i}(p)\right|}{y_{m, i}}\right)}{n}$

\section{RESULTS}

\section{SV characterization and biochemical fractionation}

The SV feed stream for Cigar in both periods of study was characterized based on samples analysed in the laboratory scale biogas plant. The average results from 2012 and 2014 are shown in Table 3. Average COD and total solids in 2014 were both twice those in 2012. This can be explained because the biorefinery produced more sugar than bioethanol in 2014/2015, leaving higher concentrations in the SV. Also high concentration of organic matter in SV is generally followed by an increase in organic acids levels, which explains about twofold of VFA in 2014 compared to 2012. 
281 Table 3. Average substrate characterization \pm standard deviation in 2012 and 2014.

\begin{tabular}{llll}
\hline Parameter & 2012 & 2014 & Units \\
\hline $\mathrm{pH}$ & $4.03 \pm 0.4$ & $4.04 \pm 0.2$ & $\mathrm{n} / \mathrm{a}$ \\
COD concentration & $30.55 \pm 11.2$ & $61.04 \pm 7.6$ & $\mathrm{~g} \mathrm{~L}^{-1}$ \\
Total solids (TS) & $24.06 \pm 7.8$ & $42.22 \pm 6.3$ & $\mathrm{~g} \mathrm{~L}^{-1}$ \\
Total volatile solids (TVS) & $17.15 \pm 7.5$ & $32.21 \pm 4.2$ & $\mathrm{~g} \mathrm{~L}^{-1}$ \\
Total suspended solids (TSS) & $11.4 \pm 8.4$ & $10.18 \pm 5.2$ & $\mathrm{~g} \mathrm{~L}^{-1}$ \\
Volatile suspended solids (VSS) & $8.22 \pm 6.3$ & $5.54 \pm 2.1$ & $\mathrm{~g} \mathrm{~L}^{-1}$ \\
Volatile fatty acids (VFA) & $2.36 \pm 0.8$ & $4.02 \pm 1.4$ & $\mathrm{~g} \mathrm{~L}^{-1}$ \\
Partial alkalinity & 0 & 0 & $\mathrm{gCaCO}_{3} \mathrm{~L}^{-1}$ \\
Total Kjeldahl nitrogen (TKN) & $0.41 \pm 0.09$ & $0.45 \pm 0.16$ & $\mathrm{~g} \mathrm{~L}^{-1}$ \\
Total ammonia nitrogen (TAN) & $0.15 \pm 0.11$ & $0.19 \pm 0.08$ & $\mathrm{gN}^{-\mathrm{NH}_{4} \mathrm{~L}^{-1}}$ \\
\hline
\end{tabular}

Table 4 shows the results of the substrate biochemical fractionation in carbohydrates $\left(f_{c h}\right)$, proteins $\left(f_{p r}\right)$, and lipids $\left(f_{l i}\right)$ on a COD basis. The carbohydrates concentration is higher than lipids and proteins as found in Barrera et al. (2015). However, it is noteworthy that protein content of the SV analysed in this study was relatively high when compared to other studies (Leite et al. 2015, Barrera et al. 2015). In the bioethanol distillery the yeast Saccharomyces cerevisiae resulting from alcohol fermentation is composed by $26.95 \%$ of crude protein, which may be lost during the process to the $\mathrm{SV}$. Another assumption for the high protein content is possibly the estimation using a constant factor of 6.25 as reported in Mariotti et al. (2008).

Table 4. Fractionation of substrate into biochemical compounds.

\begin{tabular}{lccccc}
\hline $\begin{array}{l}\text { Biochemical } \\
\text { compost }\end{array}$ & $\begin{array}{c}\text { Concentration } \\
(\mathrm{g} / \mathrm{L})\end{array}$ & $\begin{array}{c}\text { Elemental* } \\
\text { formula }\end{array}$ & $\begin{array}{c}\text { ThOD } \\
(\mathrm{gCOD} / \mathrm{gVS})\end{array}$ & $\begin{array}{c}\text { Concentration } \\
(\mathrm{gCOD} / \mathrm{L})\end{array}$ & $\left(\% \mathrm{COD}_{\text {th }}\right)$ \\
\hline Carbohydrates $\left(f_{c h}\right)$ & 4.4 & $\mathrm{C}_{6} \mathrm{H}_{10} \mathrm{O}_{5}$ & 1.184 & 5.21 & $44 \%$ \\
Proteins $\left(f_{p r}\right)$ & 2.6 & $\mathrm{C}_{5} \mathrm{H}_{7} \mathrm{O}_{2} \mathrm{~N}$ & 1.415 & 3.68 & $30 \%$ \\
Lipids $\left(f_{l i}\right)$ & 1.1 & $\mathrm{C}_{57} \mathrm{H}_{104} \mathrm{O}_{6}$ & 2.874 & 3.16 & $26 \%$ \\
\hline
\end{tabular}

*Angelidaki \& Sanders (2004)

The charge balance influences directly the reactor $\mathrm{pH}$ and its results are shown in Table 5, indicated as state variables in ADM1. Despite the fact plant operators claimed to analyse the influent frequently, necessary data to calculate $S_{\mathrm{CAT}}$ and $S_{\mathrm{AN}}$ was only found at given dates shown in Table 5 . This in turn would possibly affect the results of $\mathrm{pH}$, which is an interaction of all charge bearing species in the system, and will be discussed later. 
298 Table 5. Substrate description based on charge balance.

\begin{tabular}{|c|c|c|c|c|c|c|}
\hline \multirow[b]{2}{*}{ Date } & \multirow[b]{2}{*}{$\mathrm{pH}$} & \multirow[b]{2}{*}{$\begin{array}{l}\mathrm{VFA}-S_{\mathrm{ac}} \\
\left.(\mathrm{gCOD} \mathrm{L})^{-1}\right)\end{array}$} & \multicolumn{4}{|c|}{ ADM1 state variables } \\
\hline & & & $\begin{array}{c}S_{\mathrm{IC}} \\
\left(\mathrm{kmol} \mathrm{m}^{-3}\right)\end{array}$ & $\begin{array}{c}S_{\mathrm{IN}} \\
\left(\mathrm{kmol} \mathrm{m}^{-3}\right)\end{array}$ & $\begin{array}{c}S_{\mathrm{CAT}} \\
\left(\mathrm{kmol} \mathrm{m}^{-3}\right)\end{array}$ & $\begin{array}{c}S_{\mathrm{AN}} \\
\left(\mathrm{kmol} \mathrm{m}^{-3}\right)\end{array}$ \\
\hline \multicolumn{7}{|c|}{2012} \\
\hline 05/09 & 4.15 & 2.793 & 0 & 0.0117 & 0 & 0.0054 \\
\hline $02 / 10$ & 3.87 & 2.029 & 0 & 0.0117 & 0 & 0.0083 \\
\hline $09 / 10$ & 3.85 & 2.806 & 0 & 0.0122 & 0 & 0.0076 \\
\hline $16 / 10$ & 3.53 & 2.305 & 0 & 0.0196 & 0 & 0.0180 \\
\hline $23 / 10$ & 3.85 & 2.241 & 0 & 0.0086 & 0 & 0.0050 \\
\hline $30 / 10$ & 4.74 & 1.631 & 0 & 0.0089 & 0.003 & 0 \\
\hline $06 / 11$ & 4.09 & 3.525 & 0 & 0.01071 & 0 & 0.0011 \\
\hline $14 / 11$ & 4.00 & 2.664 & 0 & 0.0143 & 0 & 0.0083 \\
\hline $20 / 11$ & 4.17 & 3.563 & 0 & 0.0085 & 0.003 & 0 \\
\hline $23 / 11$ & 3.99 & 3.191 & 0 & 0.0173 & 0 & 0.0025 \\
\hline $27 / 11$ & 4.24 & 3.274 & 0 & 0.0275 & 0.001 & 0 \\
\hline \multicolumn{7}{|c|}{2014} \\
\hline 01/08 & 4.12 & 3.807 & 0 & 0.025 & 0 & $1.67 \mathrm{E}-10$ \\
\hline 06/08 & 4.21 & 7.942 & 0 & 0.0214 & 0.005 & $2.05 \mathrm{E}-10$ \\
\hline $13 / 08$ & 4.28 & 5.059 & 0 & 0.0277 & 0 & $2.41 \mathrm{E}-10$ \\
\hline $15 / 08$ & 4.47 & 5.059 & 0 & 0.0286 & 0 & $3.74 \mathrm{E}-10$ \\
\hline $27 / 08$ & 3.8 & 4.353 & 0 & 0.0338 & 0 & 7.99E-11 \\
\hline $29 / 08$ & 4.2 & 4.301 & 0 & 0.0344 & 0 & $2.01 \mathrm{E}-10$ \\
\hline 03/09 & 4.18 & 4.680 & 0 & 0.0339 & 0 & $1.92 \mathrm{E}-10$ \\
\hline 05/09 & 4.15 & 4.699 & 0 & 0.329 & 0 & $1.79 \mathrm{E}-10$ \\
\hline $10 / 09$ & 4.03 & 4.179 & 0 & 0.0274 & 0 & $1.36 \mathrm{E}-10$ \\
\hline $17 / 09$ & 4.21 & 5.322 & 0 & 0.0236 & 0 & $2.05 \mathrm{E}-10$ \\
\hline $19 / 09$ & 3.84 & 4.051 & 0 & 0.0189 & 0 & $8.76 \mathrm{E}-11$ \\
\hline $26 / 09$ & 4.19 & 2.343 & 0 & 0.0216 & 0 & $1.96 \mathrm{E}-10$ \\
\hline $01 / 10$ & 4.21 & 4.693 & 0 & 0.257 & 0 & $2.05 \mathrm{E}-10$ \\
\hline $03 / 10$ & 3.9 & 3.428 & 0 & 0.0264 & 0 & $1.01 \mathrm{E}-10$ \\
\hline $08 / 10$ & 3.45 & 3.351 & 0 & 0.0238 & 0 & $3.57 \mathrm{E}-11$ \\
\hline
\end{tabular}

299

300

Performance of the CIGAR

301 Figure 3 shows a good correlation between the average organic loading and the biogas flow rate, as 302 should be expected in a non-inhibited system. However, the biogas production tends to decline 303 relatively to the OLR in 2014. 


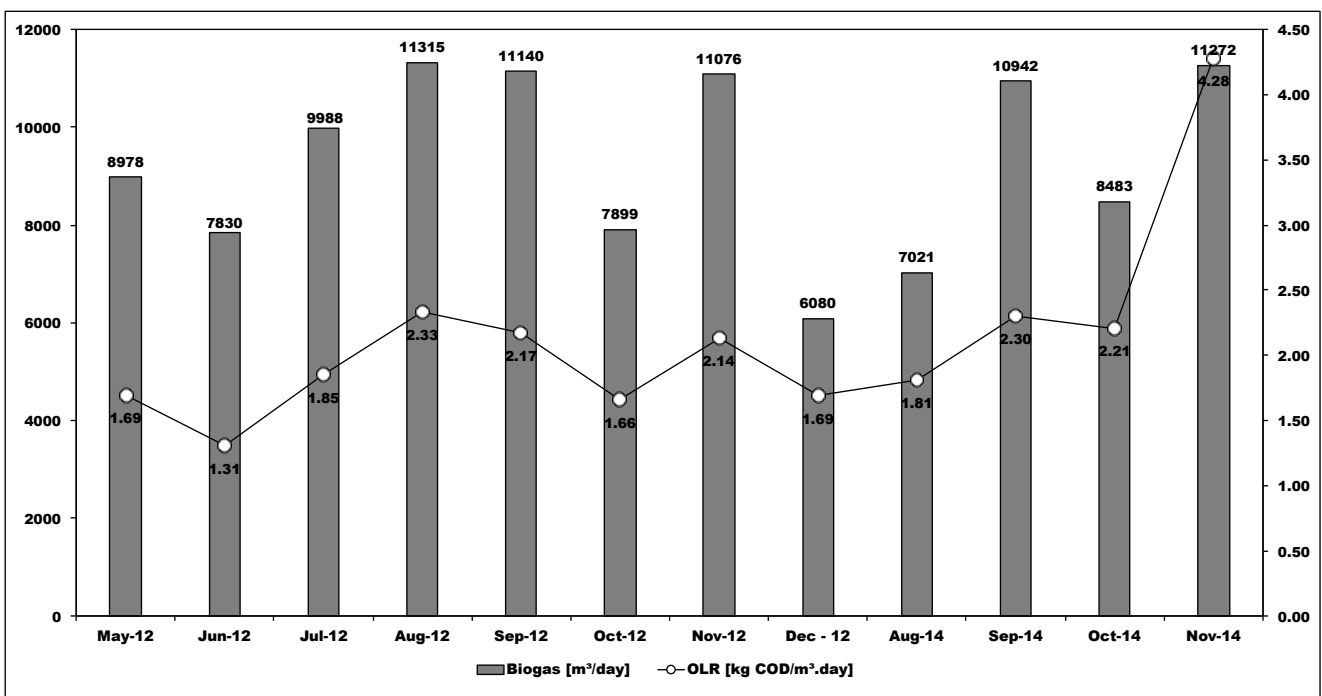

Figure 3. Averages of biogas and organic loading rate in 2012 and 2014

Ammonia inhibition is a key phenomenon affecting the dynamic of anaerobic digestion, especially

the acetoclastic methanogenesis. A wide range of inhibiting ammonia concentrations has been reported in the literature, with the inhibitory TAN concentration that caused a $50 \%$ reduction in methane production rate ranging from 1.7 to $14 \mathrm{~g} / \mathrm{L}$ (Chen et al. 2008). The inhibitory effect is due to free ammonia rather than ion ammonium: in the original ADM1 implementation, the 50\% inhibitory concentration for the free ammonia is recommended at $0.0018 \mathrm{M}$, (i.e., $25 \mathrm{mg} / \mathrm{L} \mathrm{N}-\mathrm{NH}_{3}$ ). In this study, the TAN concentration in the vinasse was, on average, 0.15 and $0.19 \mathrm{~g} / \mathrm{L}$ in 2012 and 2014 , respectively, which at an experimental average $\mathrm{pH}$ of 7.5 and at $37^{\circ} \mathrm{C}$, corresponds to a free ammonia concentration of 5.7 and $7.3 \mathrm{mg} / \mathrm{L} \mathrm{N}_{-} \mathrm{NH}_{3}$. Considering these values, it can be concluded that ammonia inhibition plays a minor role in the dynamics of the system. Furthermore, we show in Figure 3 a good correlation between the average organic loading and the biogas flow rate, as should be expected in a non-inhibited system.

\section{Initial simulations, kinetic fractionation and parameter estimation}

Initial dynamic simulations were performed to evaluate deviations between simulated and measured biogas, which are graphically evident in Figure 4 . The default value for $k_{\text {hyd }}$ and the assumed value for $f_{\mathrm{d}}$ are presented in Table 6 . Both values were reduced after parameter estimation based on biogas yield showing great sensitivity. This study confirms that default ADM1 values of $10 \mathrm{~d}^{-1}$ for hydrolysis constants are high as suggested in (Lübken et al. 2007, Vavilin et al. 2008).The 
degradability $f_{\mathrm{d}}$ of $50 \%$ estimated is consistent with the characteristics of $\mathrm{SV}$, which is composed by easily degradable organic material, mostly in the form of acetate and reducing sugars. In addition, as shown in Poggio et al. (2016) $k_{\text {hyd }}$ and $f_{\mathrm{d}}$ are correlated parameters, which leads to increased uncertainty as observed in $k_{\text {hyd. }}$ However, their correlation can offset possible adjustments between both parameters (Jensen et al. 2011).

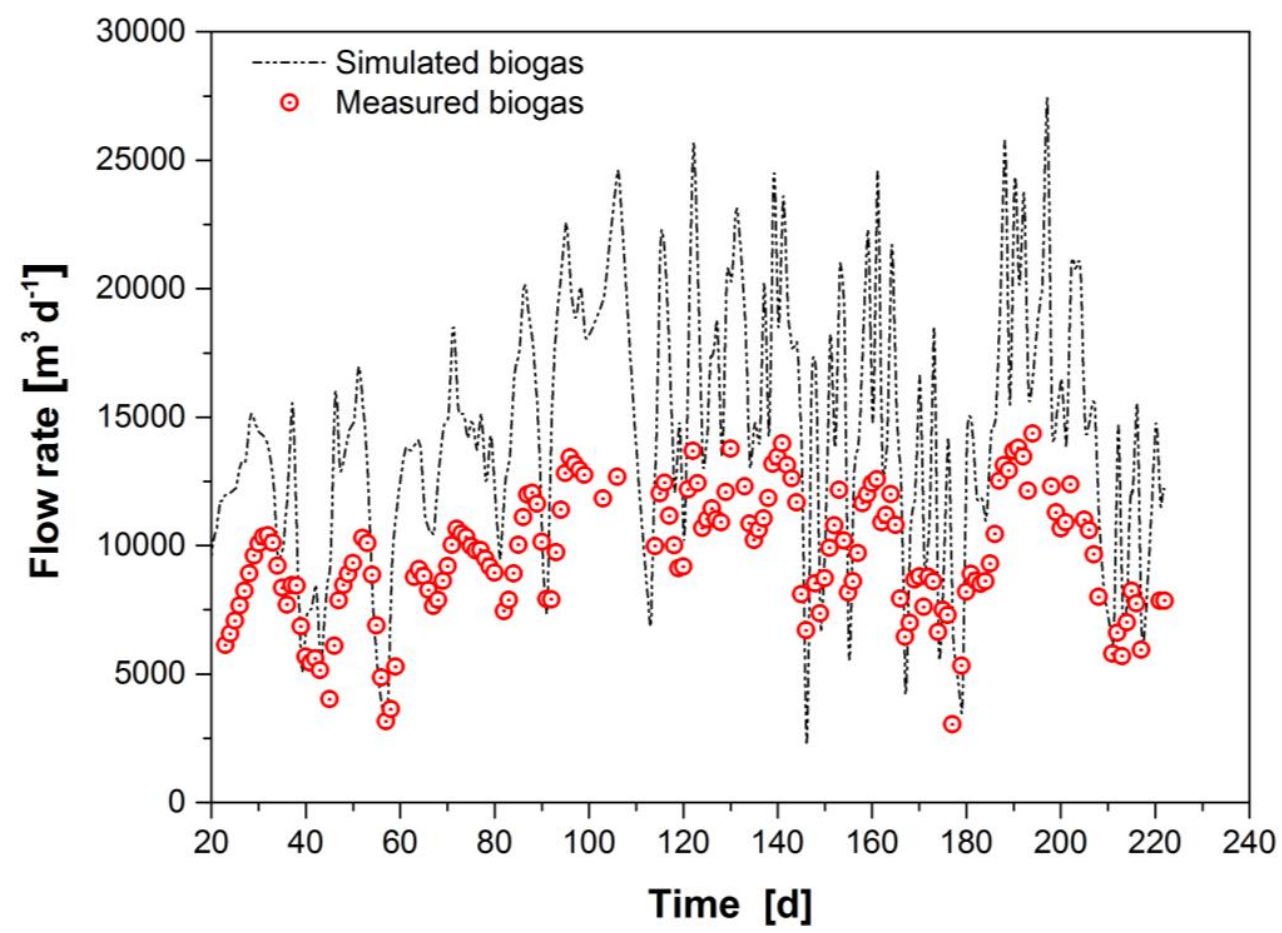

Figure 4. Initial dynamic simulations and results for measured biogas (markers) and simulated biogas (line).

Table 6. Results of model parameter estimation including intial values and standard erros.

\begin{tabular}{lccc}
\hline Parameters & Initial values & Estimated & Standard errors $(\%)$ \\
\hline$f_{\mathrm{d}}$ & $0.70^{*}$ & 0.50 & 2.7 \\
$k_{\text {hyd }}$ & $10^{\text {a }}$ & 0.66 & 18.4 \\
\hline
\end{tabular}

${ }^{\text {a ADM1 STR } * \text { assumed value }}$

\section{Direct validation}

The simulations in Figure 5 indicate that, after parameter estimation of $f_{\mathrm{d}}$ and $k_{\text {hyd }}$, there is a good fit between simulated and measured biogas. The biogas prediction was assessed as medium, regarding $18.2 \%$ of rAE. However, possible discrepancies between measurements and simulation results may be attributed to the ADM1 gas/liquid transfer coefficients for all gases, which in fact differ from reality (Ramirez et al. 2009b). 


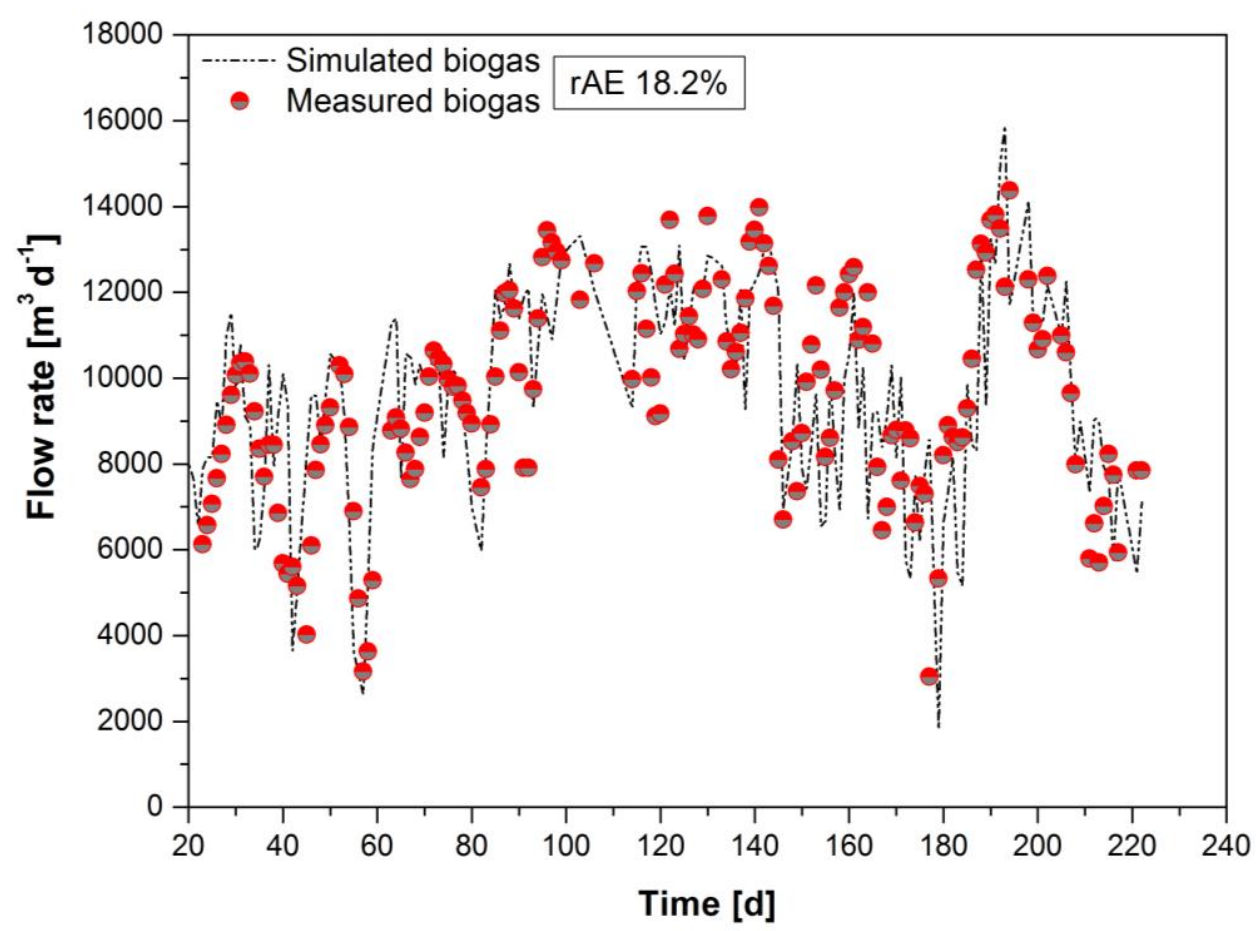

Figure 5. rAE for simulated results (line) and measured data (markers) for biogas production in 2012 - direct validation.

The deviations between simulated and measured outputs of methane and carbon dioxide levels after the parameter estimation of $f_{\mathrm{d}}$ and $k_{\text {hyd }}$ were also evaluated. The results are shown in Figure $6(\mathrm{~A})$ and 6 (B), respectively. A good fit was achieved both for methane and carbon dioxide, which is an indicator for a realistic substrate characterization (Lübken et al. 2007). These predictions were assessed as high accuracy quantitative for methane with $6.8 \%$ of rAE and medium for carbon dioxide with $11.4 \%$ of rAE.
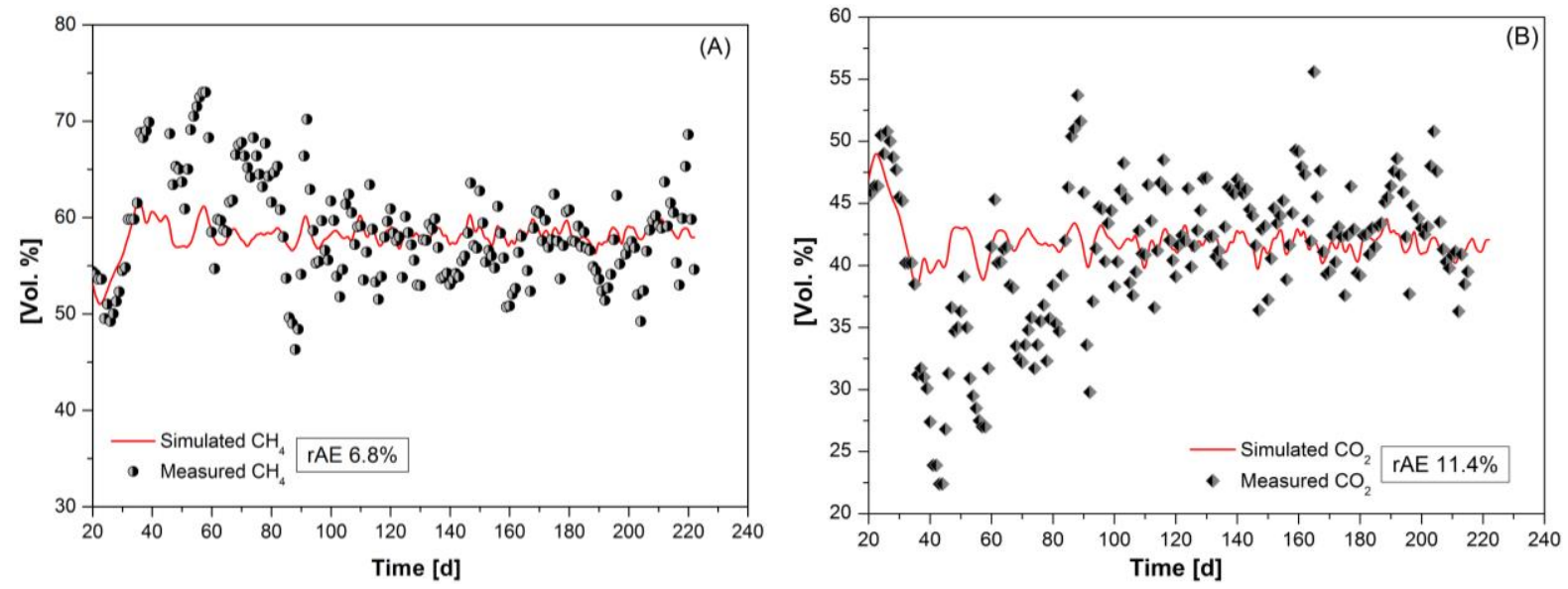

Figure 6. rAE for simulated results (line) and measured data (markers) for methane (A) and carbon dioxide (B) - direct validation. 
The difference between the concentrations of anions and cations calculated in the feeds predicts the

$355 \mathrm{pH}$ in the system (Ramirez et al. 2009b). The simulations of $\mathrm{pH}$ variable, shown in Figure 7 (A) and 3566 (B), tend to underestimate the $\mathrm{pH}$ in both periods. This lack of fit could be explained by possible inaccuracies in the description of the charge balance of the substrate, with cations and anions loading, being calculated only during the dates presented in Table 5; apart from these dates yearly average values were used. Only between day 20 and 30 for the period of 2012 the model was able to improve the fit.
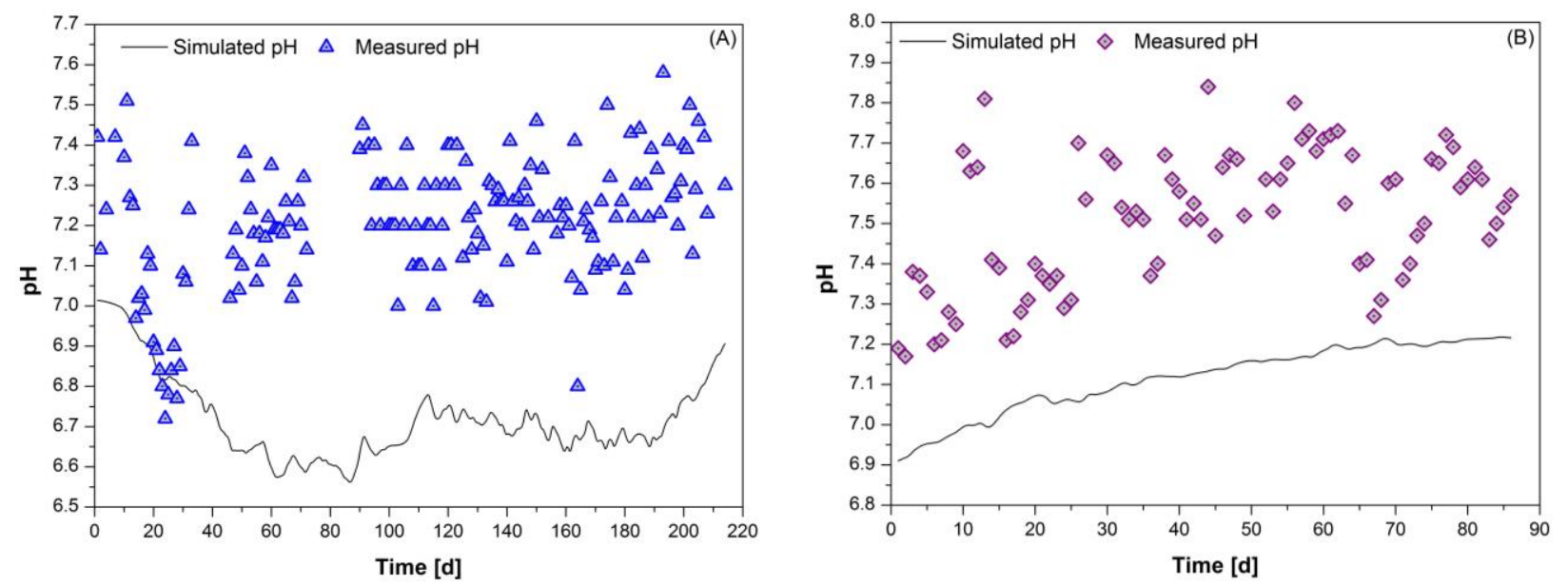

Figure 7. Simulated results (line) and measured data (markers) for $\mathrm{pH}$ in both periods under study: 2012 (A) and 2014 (B).

The model tends to over predict the COD concentrations (Figure 8), although, the trend is qualitatively followed by an increase in the COD concentrations.

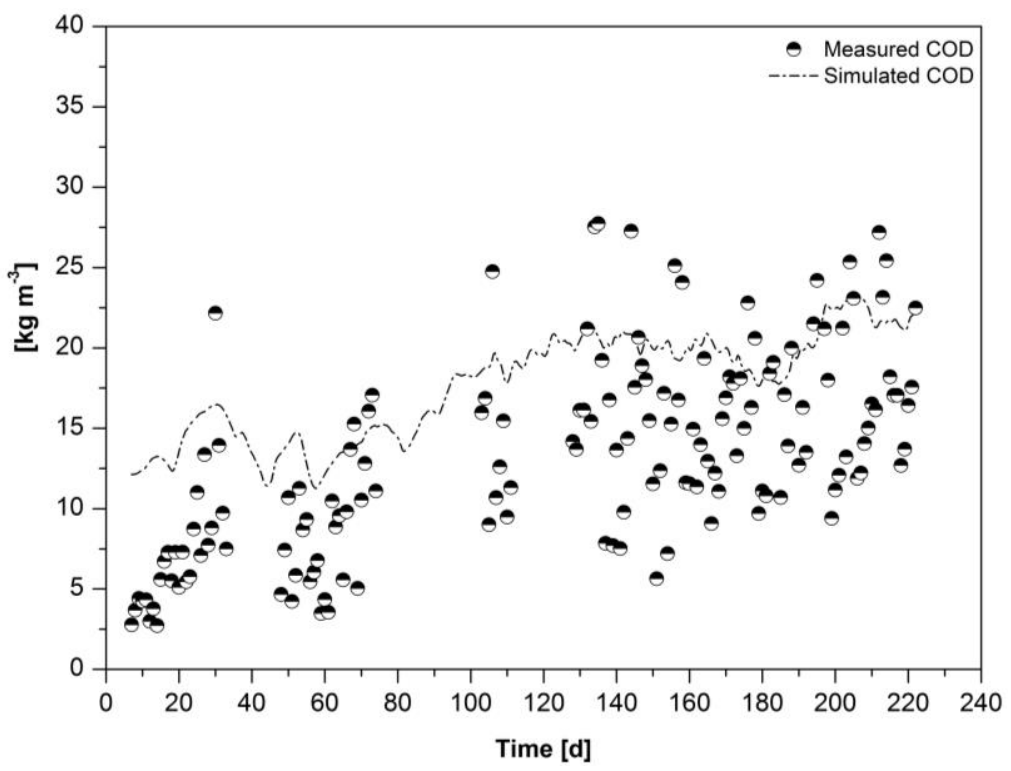

Figure 8. Simulated results (line) and measured data (markers) for COD concentrations in 2012. 
The cross validation procedure was implemented to check whether the model gives a reliable picture of the quality of the prediction on a second dataset after parameter estimation. To this end, the same values for the estimated parameters were kept in the cross validation. The Cigar operation summed up 96 days in 2014 under the same setup previously described in 2012.

As presented in Figure 9, samples of biogas in 2014 are fewer than in 2012 but do so clearly and visibly a good fit between measured and simulated biogas. At the same time, the quality of biogas prediction was classified as medium accuracy showing a higher error (rAE 20\%) resulting in a lower quality of prediction. This suggests that an increased solids concentration in the vinasse in 2014, as observed in Table 3, compared to 2012 may be affecting the estimated hydrolysis constants of $0.66 \mathrm{~d}^{-1}$, which are sensitive to solids concentration (Köch et al. 2010).

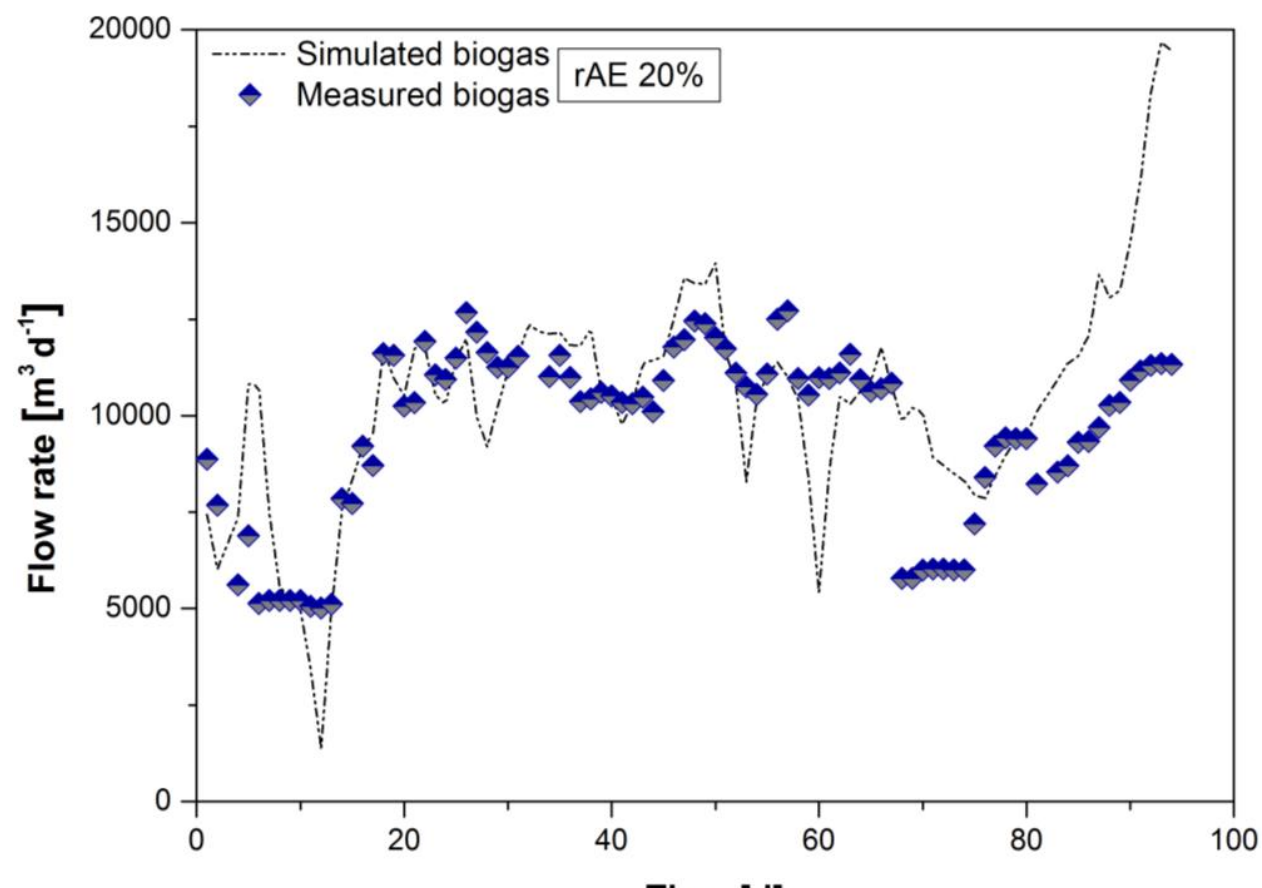

Figure 9. rAE for simulated results (line) and measured data (markers) for biogas production in 2014 - cross validation.

The rAE of $6.6 \%$ and $8 \%$ for methane and carbon dioxide, respectively, confirm the well fitted visual impression of the plots in Figure 10 (A) and 10 (B). The error for methane in the cross validation (rAE 6.6\%) was quite similar to direct validation (rAE 6.8\%), and validates the value of the estimate degradation extent $\left(f_{\mathrm{d}}\right)$ describing the degradable ThOD fraction of substrate that is converted to methane. Again, followed by a lower error (rAE 8\%) for carbon dioxide in the cross 

substrate characterization (Lübken et al. 2007).
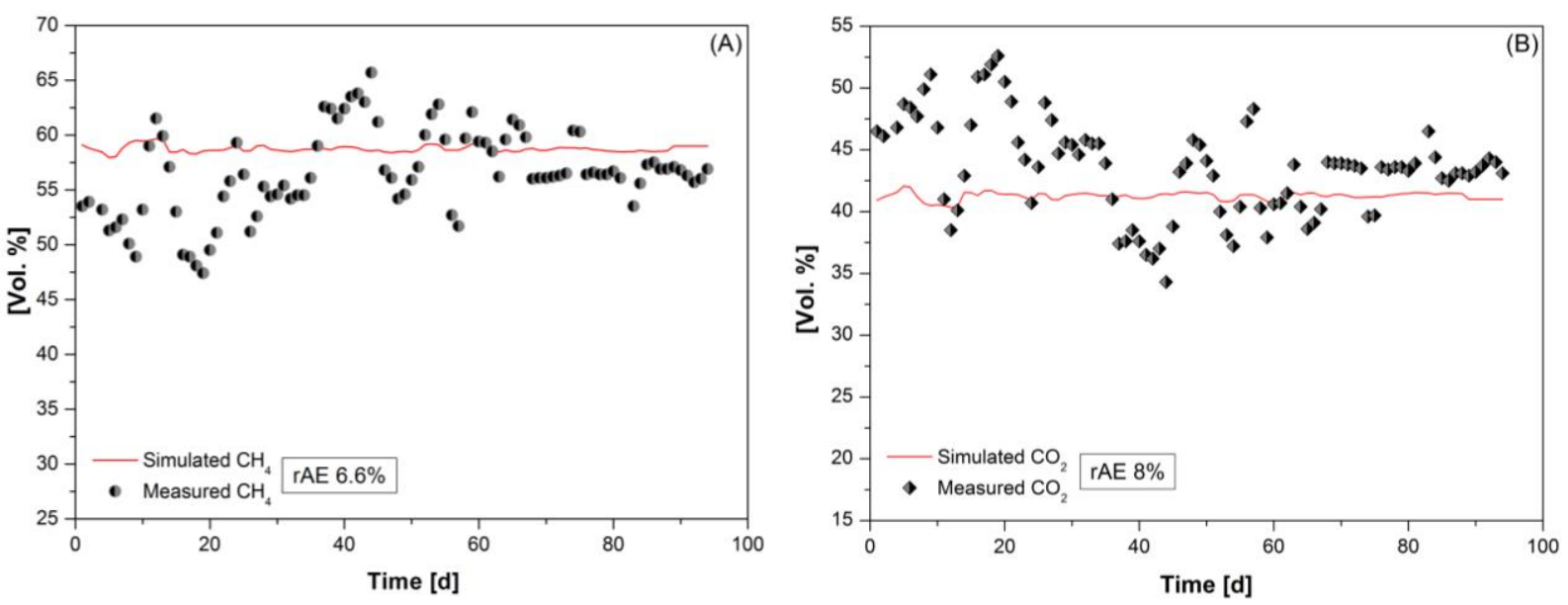

Figure 10. rAE for simulated results (line) and measured data (markers) for (A) methane and (B) carbon dioxide - cross validation.

As noted in Figure 11, there were significant fluctuations in the measured COD concentrations that could not be explained by the model in 2014 . This result suggests that possibly, some parameters not calibrated in this study are reflecting an inconsistency between simulated and measured COD concentrations.

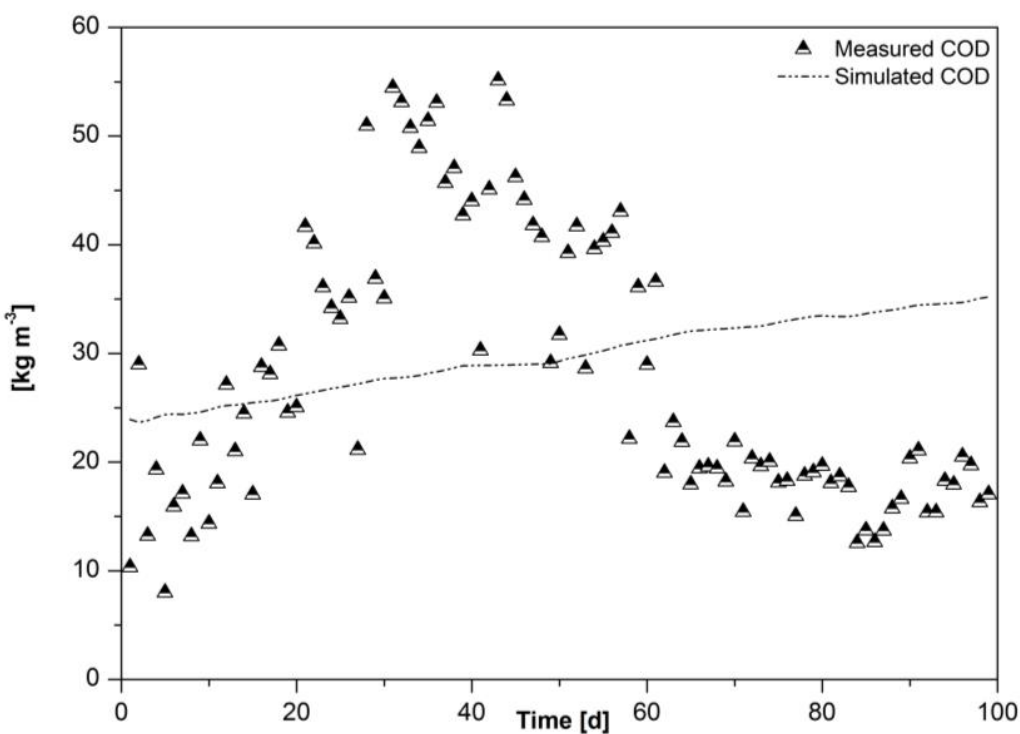

Figure 11. Simulated results (line) and measured data (markers) for COD concentrations in 2014. 
403 Motivated by practical and industrial application of ADM1, for both different reactors types and substrates, we have demonstrated in a clear procedure the implementation of ADM1 to specific large-scale reactor for anaerobic digestion of sugarcane vinasse. The substrate characterization for ADM1 in terms of its biochemical make-up (i.e., carbohydrates, proteins, and lipids), based on the food industry standards were found to be valid when applied to describe sugarcane vinasse. The quality of the predictions supported by the uncertainty of the estimation of the parameters, as given by their calculated standard errors, provides a trustworthy assessment of the model performance on future data. However, the lack of data to provide ADM1 charge balance inputs to cover all dynamic feed streams resulted in poor $\mathrm{pH}$ simulations.

Therefore, taking into account the scale of the reactor presented here and the complexity of ADM1, a practical industrial application to model a large-scale anaerobic digester under dynamic feed streams, is a useful tool to predict the biogas yields and its composition.

Arnell, M., Astals, S., Åmand, L., Batstone, D. J., Jensen, P. D. \& Jeppsson, U. 2016 Modelling anaerobic co-digestion in Benchmark Simulation Model No. 2: Parameter estimation, substrate characterisation and plant-wide integration. Water Research, 98 (2), 138-146. DOI:10.1016/j.watres.2016.03.070.

Angelidaki, I. \& Sanders, W. 2004. Assessment of the anaerobic biodegradability of macropollutants. Reviews in Environmental Science \& Biotechnoly, 3, 117-129. DOI:10.1007/s11157-004-2502-3.

APHA/AWWA/WEF 2012 Standard Methods for the Examination of Water and Wastewater, 22nd edn. American Public Health Association/American Water Works Association/Water Environment Federation, Washington, DC, USA. 
Barrera, E. L., Spanjers, H., Solon, K., Amerlinck, Y., Nopens, I. \& Dewulf, J. 2015 Modeling the anaerobic digestion of cane-molasses vinasse: Extension of the Anaerobic Digestion Model No. 1 (ADM1) with sulfate reduction for a very high strength and sulfate rich wastewater. Water Research, 71 (1), 42-54. DOI:10.1016/j.watres.2014.12.026.

Batstone, D. J. \& Keller, J. 2003 Industrial applications of the IWA anaerobic digestion model No.1 (ADM1). Water Science and Technology, 47 (12), 199-206.

Batstone, D. J., Keller, J. \& Steyer, J. P. 2006 A review of ADM1 extensions, applications, and analysis: 2002-2005. Water Science and Technology, 54 (4), 1-10. DOI:10.2166/wst.2006.520.

Batstone, D. J. \& Steyer, J. P. 2007 Use of modelling to evaluate best control practice for winerytype wastewaters. Water Science and Technology, 56 (2), 147-152. DOI:10.2166/wst.2007.483.

Batstone, D. J., Tait, S. \& Starrenburg, D. 2009 Estimation of hydrolysis parameters in full-scale anerobic digesters. Biotechnology and Bioengineering, 102 (5), 1513-1520. DOI:10.1002/bit.22163.

Batstone, D. J., Balthes C. \& K. Barr 2010 Model assisted startup of anaerobic digesters fed with thermally hydrolysed activated sludge. Water Science and Technology, 62 (7), 1661 - 1666. DOI:10.2166/wst.2010.487.

Batstone, D. J., Keller, J., Angelidaki, I., Kalyuzhnyi, S., Pavlostathis, S., Rozzi, A., Sanders, W. T., Siegrist, H. \& Vavilin, V. 2002 The IWA Anaerobic Digestion Model No 1(ADM1). Water Science and Technology, 45 (1), 65-73. DOI:10.2166/wst.2008.678.

Bligh, E. G. \& Dyer, W. J. 1959 Canadian Journal of Biochemistry and Physiology, 37 (8), 911917.

Chen, Y., Cheng, J. J. \& Creamer, K. S. 2008 Inhibition of anaerobic digestion process: A review. Bioresource Technology 99 (10), 4044-4064. DOI:10.1016/j.biortech.2007.01.057

Donoso-Bravo, A., Mailier, J., Martin, C., Rodríguez, J., Aceves-Lara, C. A. \& Wouwer A. V. 2011 Model selection, identification and validation in anaerobic digestion: A review. Water Research, 45 (17), 5347-5364. DOI:10.1016/j.watres.2011.08.059.

Flores-Alsina, X., Kimberly, S., Mbamba, C. K., Tait, S., Gernaey, K. V., Jeppsson, U. \& Batstone, D. J. (2016) Modelling phosphorus (P), sulfur (S) and iron ( $\mathrm{Fe})$ interactions for dynamic simulations of anaerobic digestion processes. Water Research, 95, 370-382. DOI:10.1016/j.watres.2016.03.012.

GAIN (Global Agricultural Information Network). Brazil Suggar Annual (2017) <https://gain.fas.usda.gov/Recent\%20GAIN\%20Publications/Sugar\%20Annual_Sao\%20Paulo \%20ATO_Brazil_4-19-2017.pdf> (accessed 7 May 2017).

Heertjes, P. M. \& Kuijvenhoven, L. J. 1982 Fluid flow pattern in upflow reactors for anaerobic treatment of beet sugar factory wastewater. Biotechnology and Bioengineering, XXIV, 443459.

Jensen, P. D., Ge, H. \& Batstone, D. J. 2011 Assessing the role of biochemical methane potential tests in determining anaerobic degradability rate and extent. Water Science and Technology, 64 (4), 880-886. DOI:10.2166/wst.2011.662.

Kazadi Mbamba C., Flores-Alsina X., Batstone, D. J. \& Tait, S. 2016 Validation of a plant-wide phosphorus modelling approach with minerals precipitation in a full-scale WWTP. Water Research, 100, 169-183. DOI:10.1016/j.watres.2016.05.003.

Köch, K., Lübken, M., Gehring, T., Wichern, M. \& Horn, H. 2010 Biogas from grass silage - 
Measurements and modeling with ADM1. Bioresource Technology, 101 (21), 8158-8165. DOI:10.1016/j.biortech.2010.06.009.

Lane, J. \& Eynon, L. 1923 Volumetric determination of reducing sugars by means of Fehling's solution with methylene blue as indicator. Journal of the Society of Chemical Industry, XXV, 143-149.

Leite, A. F., Janke, L., Harms, H., Zang, J. W., Fonseca-Zang, W. A., Stinner, W. \& Nikolausz, M. 2015 Assessment of the Variations in Characteristics and Methane Potential of Major Waste Products from the Brazilian Bioethanol Industry along an Operating Season. Energy and Fuels, 29 (7), 4022-4029. DOI:10.1021/ef502807s.

Lübken, M., Wichern, M., Schlattmann, M., Gronauer, A. \& Horn, H. 2007 Modelling the energy balance of an anaerobic digester fed with cattle manure and renewable energy crops. Water Research, 41 (18), 4085-4096. DOI:10.1016/j.watres.2007.05.061.

Mariotti, F., Tomé, D. \& Mirand, P. P. Converting Nitrogen into Protein - Beyond 6.25 and Jones' Factors. Critical Reviews in Food Science and Nutrition, 48 (2), 177-184, DOI:10.1080/10408390701279749.

Mata-Alvarez, J., Dosta, J., Macé, S. \& Astals, S. 2011 Codigestion of solid wastes: A review of its uses and perspectives including modeling. Critical Reviews in Biotechnology, 31 (2), 99-111. DOI: $10.3109 / 07388551.2010 .525496$.

Moraes, B. S., Zaiat, M. \& Bonomi, A. 2015 Anaerobic digestion of vinasse from sugarcane ethanol production in Brazil: Challenges and perspectives. Renewable and Sustainable Energy Reviews, 44, 888-903. DOI:10.1016/j.rser.2015.01.023.

Nopens, I., Batstone, D. J., Copp, J. B., Jeppsson, U., Volcke, E., Alex, J., \& Vanrolleghem, P. A. 2009 An ASM/ADM model interface for dynamic plant-wide simulation. Water Research, 43 (7), 1913-1923. DOI:10.1016/j.watres.2009.01.012.

Peña, M. R., Mara, D. D. \& Avella, G. P. 2006 Dispersion and treatment performance analysis of an UASB reactor under different hydraulic loading rates. Water Research, 40, 445-452. DOI:10.1016/j.watres.2005.11.021.

Poggio, D., Walker M., Nimmo, W., Ma, L. \& Pourkashanian, M. 2016 Modelling the anaerobic digestion of solid organic waste - Substrate characterisation method for ADM1 using a combined biochemical and kinetic parameter estimation approach. Waste Management, 53, 40-54. DOI:10.1016/j.wasman.2016.04.024.

Pratt, S., Liew, D., Batstone, D. J., Werker, A. G., Morgan-Sagastume, F. \& Lant, P. A. 2012 Inhibition by fatty acids during fermentation of pre-treated waste activated sludge. Journal of Biotechnology, 159 (1-2), 38-43. DOI:10.1016/j.jbiotec.2012.02.001.

Ramirez, I., Mottet, A., Carrère, H., Déléris, S., Vedrenne, F. \& Steyer, J. P. 2009a Modified ADM1 disintegration/hydrolysis structures for modeling batch thermophilic anaerobic digestion of thermally pretreated waste activated sludge. Water Research, 43 (14), 3479-3492. DOI: $10.1016 /$ j.watres.2009.05.023.

Ramirez, I., Volcke, E. I. P., Rajinikanth, R. \& Steyer, J.P. 2009b Modeling microbial diversity in anaerobic digestion through an extended ADM1 model. Water Research, 43 (11), 2787-800. DOI: $10.1016 /$ j.watres.2009.03.034.

Reichert, P. 1998 Computer Program for the Identification and Simulation of Aquatic Systems (AQUASIM), Swiss Federal Institute for Environmental Science and Technology, Dübendorf, Switzerland. 
Rosén, C. \& Jeppsson, U. 2006 Aspects on ADM1 Implementation within the BSM2 Framework. Department of Industrial Electrical Engineering and Automation, Lund University, Lund, Sweden.

Solon, K., Flores-Alsina, X., Kazadi-Mbamba, C., Volcke, E.I.P., Tait, S., Batstone, D. J., Gernaey, K.V. \& Jeppsson, U. 2015 Effects of ion strength and ion pairing on (plant-wide) modelling of anaerobic digestion processes. Water Research, 70, 235-245. DOI:10.1016/j.watres.2014.11.035.

Solon, K. 2017 Extending Wastewater Treatment Process Models for Phosphorus Removal and Recovery - A Framework for Plant-Wide Modelling of Phosphorus, Sulfur and Iron. PhD Thesis, Division of Industrial Electrical Engineering and Automation, Faculty of Engineering, Lund University, Sweden.

Vavilin, V. A., Fernandez, B., Palatsi, J. \& Flotats, X. 2008 Hydrolysis kinetics in anaerobic degradation of particulate organic material: An overview. Waste Management, 28 (6), 939951. DOI:10.1016/j.wasman.2007.03.028.

Wett, B., Takács, I., Batstone, D. J., Wilson, C. \& Murthy, S. 2014 Anaerobic model for highsolids or high-temperature digestion-additional pathway of acetate oxidation. Water Science and Technology, 69 (8) 1634-1640. DOI:10.2166/wst.2014.047.

Wilson, C. A., Novak, J., Takacs, I., Wett, B., \& Murthy, S. 2012 The kinetics of process dependent ammonia inhibition of methanogenesis from acetic acid. Water Research, 46 (19), 6247-6256. DOI:10.1016/j.watres.2012.08.028 